\title{
CENÁRIO DA AGRICULTURA FAMILIAR NO TERRITÓRIO SERTÃO PRODUTIVO, CANDIBA - BA
}

\author{
Elcivan Pereira Oliveira', Brisa Ribeiro de Lima', Felizarda Viana Bebé² e Priscila \\ Alves de Lima $^{3}$ \\ ${ }^{1}$ Graduando em Agronomia, Instituto Federal de Educação, Ciência e Tecnologia \\ Baiano, Campus Guanambi, BA - Brasil. E-mail: elcivan_gbi@hotmail.com; \\ ${ }^{2}$ Professora Doutora, Instituto Federal de Educação, Ciência e Tecnologia Baiano, \\ Campus Guanambi, BA - Brasil; \\ ${ }^{3}$ Doutora, Bolsista do CNPq e Instituto Federal de Educação, Ciência e Tecnologia \\ Baiano, Campus Guanambi, BA - Brasil.
}

\section{Recebido em: 03/10/2016 - Aprovado em: 21/11/2016 - Publicado em: 05/12/2016 DOI: 10.18677/EnciBio 2016B 023}

\begin{abstract}
RESUMO
A agricultura familiar é um setor estratégico no âmbito econômico e social. Sua caracterização torna-se pertinente para a elaboração de políticas públicas para o desenvolvimento rural. Neste sentido, objetivou-se delinear o cenário da agricultura familiar no município de Candiba-BA no território Sertão Produtivo. O estudo foi realizado com agricultores de uma comunidade do município. Para o levantamento dos dados foram aplicados questionários semi-estruturados, sem identificação individual do agricultor, com questões que possibilitaram a extração de variáveis quantitativas e qualitativas. Os resultados obtidos revelam a predominância de pequenas propriedades e produção agrícola típica familiar. Todos os agricultores já foram ou estão sendo contemplados por créditos agrícolas e $88 \%$ já se beneficiaram com as cisternas do programa Água para Todos do governo federal. Entretanto, a produção familiar é comprometida pela falta de assistência técnica rural que reflete no uso indiscriminado de agrotóxicos e práticas agrícolas inadequadas. A agricultura familiar tem importante destaque, tanto na economia interna do município e territorial quanto no trabalho das pessoas e na garantia da população a ter acesso aos alimentos.
\end{abstract}

PALAVRAS-CHAVE: assistência técnica, políticas públicas, produção familiar

\section{SCENARIO OF THE FAMILY FARM IN TERRITORY SERTÃO PRODUTIVO, CANDIBA - BA}

\begin{abstract}
Family farming is a strategic sector in the economic and social context. Characterization becomes relevant to the development of public policies for rural development. In this sense, the objective of this study was to design the scenario of family farming in Candiba-BA municipality in the territory Sertão Produtivo. The study was conducted with farmers in a county community. For the data collection semistructured questionnaires were applied, without individual identification of the farmer with issues that enabled the extraction of quantitative and qualitative variables. The results show the predominance of small farms and family typical agricultural production. All farmers have been or are being contemplated by agricultural credits
\end{abstract}


and $88 \%$ have already benefited from the tanks of the Water for All program of the federal government. However, the family production is compromised by lack of rural technical assistance that reflects the indiscriminate use of pesticides and inappropriate agricultural practices. Family farming is important to highlight, both in the municipal and territorial domestic economy as the work of the people and ensuring people have access to food.

KEYWORDS: family production, technical assistance, public policy

\section{INTRODUÇÃO}

No cenário que compõe o meio rural, o agricultor familiar surge como protagonista de importância econômica e social. A agricultura familiar é um setor estratégico para a manutenção e recuperação do emprego, fator redutor do êxodo rural e fonte de recursos para as famílias com menor renda. A produção familiar contribui expressivamente para a geração de riqueza e para a construção do desenvolvimento sustentável, além de atuar na redistribuição da renda e garantir a soberania alimentar do país (SANTOS et al., 2013).

A agricultura familiar é responsável por grande parte da produção de alimentos e abarca o maior número de produtores rurais no Brasil. Conforme dados do último Censo Agropecuário do IBGE (2006), 74,4\% dos trabalhadores rurais são agricultores familiares. Somados, correspondem a mais de 12 milhões de brasileiros, que são responsáveis por mais de $70 \%$ dos alimentos produzidos e consumidos diariamente na mesa da população nacional. Assim, há um destaque desse setor na produção de alimentos.

A produção familiar é a principal atividade econômica de várias regiões do país e apresenta suma importância social, econômica e ambiental. O Nordeste possui 2.187.295 estabelecimentos e 35,3\% da área total deles. Além disso, cinco dos dez maiores estados brasileiros em termos de número de estabelecimentos de agricultura familiar são nordestinos, com destaque para Bahia, em primeiro lugar, com 665.831 (ou 15,2\% do total nacional) (IBGE, 2006).

Neste cenário, o município de Candiba localizado no território de identidade Sertão Produtivo, estado da Bahia, possui uma área de $418.000 \mathrm{~km}^{2}$ abrigando uma população estimada de 14.732 habitantes com 42\% residindo na zona rural (IBGE, 2016). Os estabelecimentos rurais deste território são compostos, em sua maioria, por áreas pequenas e de agricultura familiar que apesar de enfrentar problemas como a irregularidade das chuvas e escassez de assistência técnica e extensão rural, é responsável por 90\% da economia da região (MDA, 2010).

De acordo Ferreira et al. (2009), a caracterização da agricultura familiar em regiões pouco estudadas torna-se pertinente, uma vez que pode se tornar um instrumento para os gestores daquele município para a elaboração de políticas de desenvolvimento rural adequadas a realidade local. Desta forma, objetivou-se delinear o cenário da agricultura familiar no município de Candiba-BA no território Sertão Produtivo.

\section{MATERIAL E MÉTODOS}

O trabalho foi realizado com os agricultores familiares de uma comunidade presente no município de Candiba (14\% $23^{\prime}$ sul e $42^{\circ} 53^{\prime}$ Oeste), integrante do território de identidade Sertão Produtivo, estado da Bahia. A comunidade situa-se a aproximadamente $3 \mathrm{~km}$ da sede do município e foi fundada em 1994. 
Inicialmente realizou-se uma conversa informal, no intuito de apresentar os objetivos do trabalho e buscar reconhecer as características gerais e os aspectos sociais da comunidade. Na ocasião, os entrevistados descreveram a realidade local e relataram suas experiências, gerando uma discussão sobre os principais problemas e potencialidades da comunidade.

Em outra visita a comunidade, aplicou-se um questionário semi-estruturado, sem identificação individual, com 38 questões, que possibilitou a extração de variáveis quantitativas e qualitativas. Os agricultores foram questionados sobre os aspectos sociais, manejo agrícola praticado, divisão do trabalho familiar, os créditos rurais e a infraestrutura disponível.

Os questionários foram constituídos de perguntas objetivas e subjetivas, que obedeceram aos critérios coloquiais, usando o máximo de expressões conhecidas pelos agricultores. Após a aplicação dos questionários sem a identificação pessoal, os dados levantados foram agrupados, tabulados, analisados por meio de estatística descritiva.

\section{RESULTADOS E DISCUSSÃO}

A comunidade é formada por 50 associados, em que cerca de $90 \%$ residem na comunidade e os demais na sede do município. Entre as famílias que preencheram o questionário, 63\% são patriarcas (chefiadas por homens) e $37 \%$ são conjuntas (chefiadas pelo casal), o termo "chefiadas" se caracteriza na pesquisa como pessoa responsável pela administração da casa e da propriedade. Todos os agricultores são casados, o que evidencia a valorização do matrimônio.

A Unidade de Produção Familiar (UPF) caracteriza-se pelo conjunto de trabalho, propriedade e família. As UPF do município são compostas em sua maioria por três e quatro pessoas que representam 31 e $37 \%$, respectivamente (Figura 1). Sendo o número médio de habitantes por UPF de 3,44 pessoas.

A força de trabalho nas UPF é exclusivamente familiar em $25 \%$ das propriedades, com $69 \%$ dos agricultores contratando diaristas no período de maior demanda de trabalho e $6 \%$ fazem troca de serviços com outros produtores, o que reforça ainda mais a típica produção familiar.

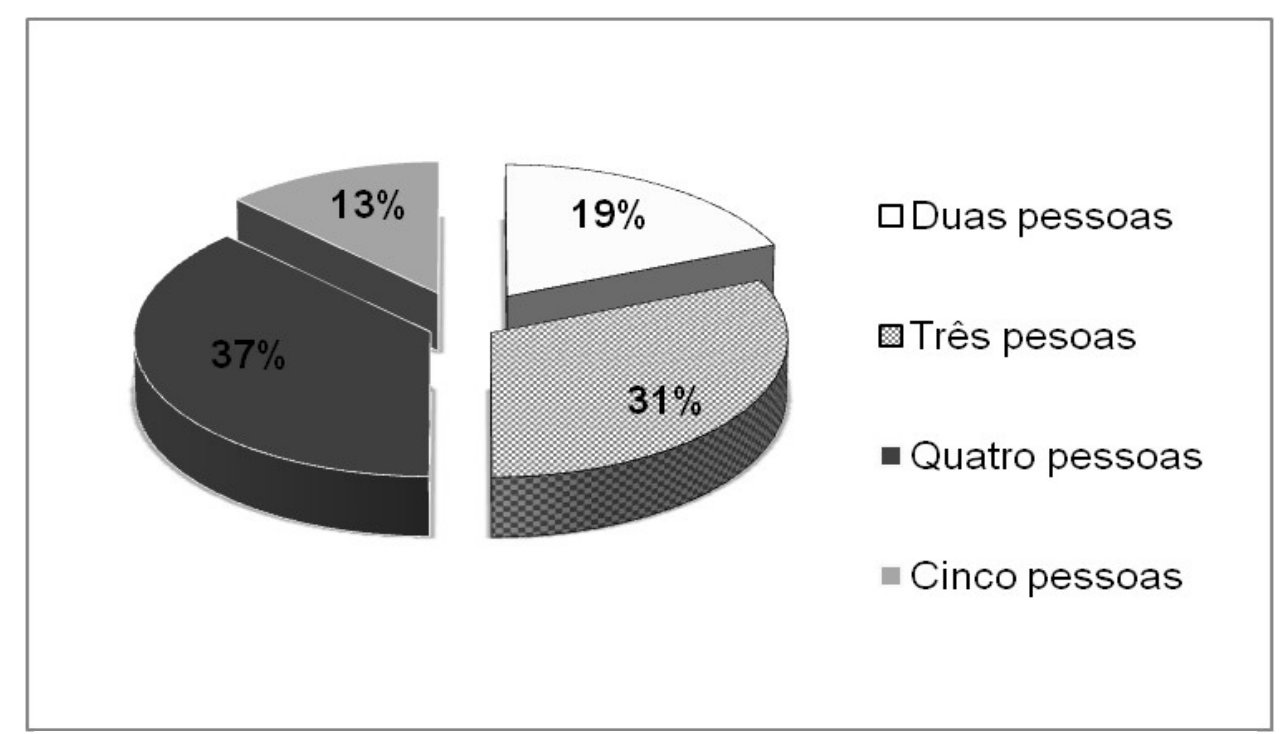

FIGURA 1. Número de moradores por unidades de produção familiar em Candiba-BA, 2016. 
De acordo com a Constituição Federal Brasileira, lei 11.326/06, o agricultor familiar deve possuir no máximo quatro módulos fiscais e conforme o INCRA (2016), um módulo fiscal no município equivale a 65 ha. As propriedades dos agricultores entrevistados apresentaram extensão variável (Figura 2). No entanto, $75 \%$ das propriedades possuem área variando de 0 a 5 ha e as demais até 20 ha. Os resultados revelam a adequação das áreas à lei que estabelece as diretrizes da agricultura familiar no Brasil e reforça uma das principais características da produção familiar da região que é a predominância de pequenas propriedades.

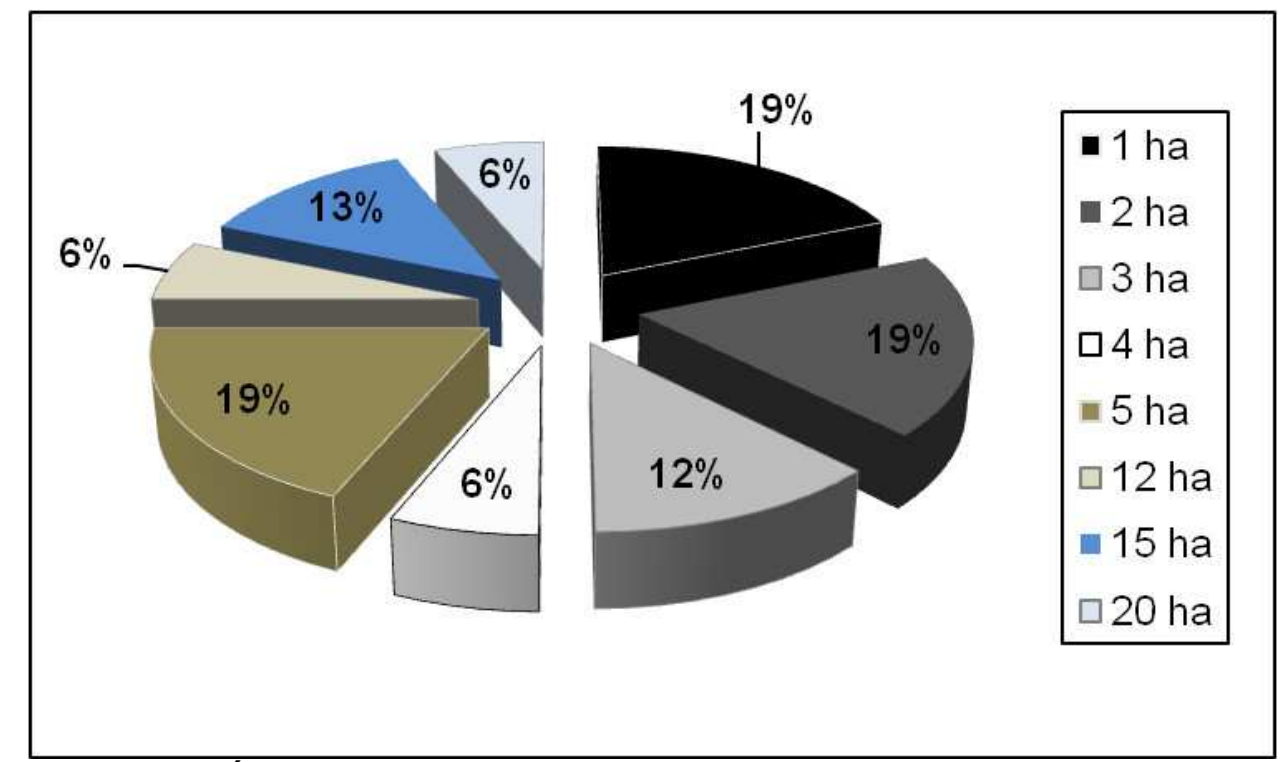

FIGURA 2. Área das unidades de produção familiar de Candiba-BA, 2016.

Dentre as atividades agrícolas praticadas pelos agricultores familiares, destacam-se os cultivos de feijão caupi (Vigna unguiculata), sorgo forrageiro, hortaliças (alface, cebola, coentro e salsa), melancia e mandioca, participando de $62,50,25,18$ e $12 \%$ da produção agrícola familiar, respectivamente. Nenhum agricultor realiza análise do solo para fins de fertilidade e a adubação, quando ocorre, é realizada sem nenhum parâmetro químico ou físico. As culturas anuais como o feijão, sorgo forrageiro, mandioca são cultivadas sem o uso de adubação. Enquanto que nas áreas com hortaliças ocorre apenas adubação orgânica e as de melancia, tanto orgânica quanto mineral.

As espécies cultivadas são típicas da agricultura familiar, com produtos que vão direto para a mesa do consumidor, sendo a produção destinada principalmente ao consumo da família e alimentação de ruminantes durante a época da seca (sorgo forrageiro). Entretanto, o excedente é comercializado com a finalidade de adquirir renda para obtenção de produtos que não são produzidos no estabelecimento familiar.

A produção excedente é $37 \%$ destinada à feira livre do município e $6 \%$ vendida pelo agricultor de casa em casa, para consumidores fixos, entretanto, mais da metade dos agricultores familiares ainda são dependentes de atravessadores para comercializar a produção excedente (Figura 3). De acordo com NASCIMENTO \& BESKOW (2015), para agricultura familiar, a comercialização direta, por meio de feiras, é a mais adequada para a distribuição de seus produtos, visto que, proporciona aproximações de produtores e consumidores e possibilita maiores ganhos ao agricultor e menor preço ao consumidor. 


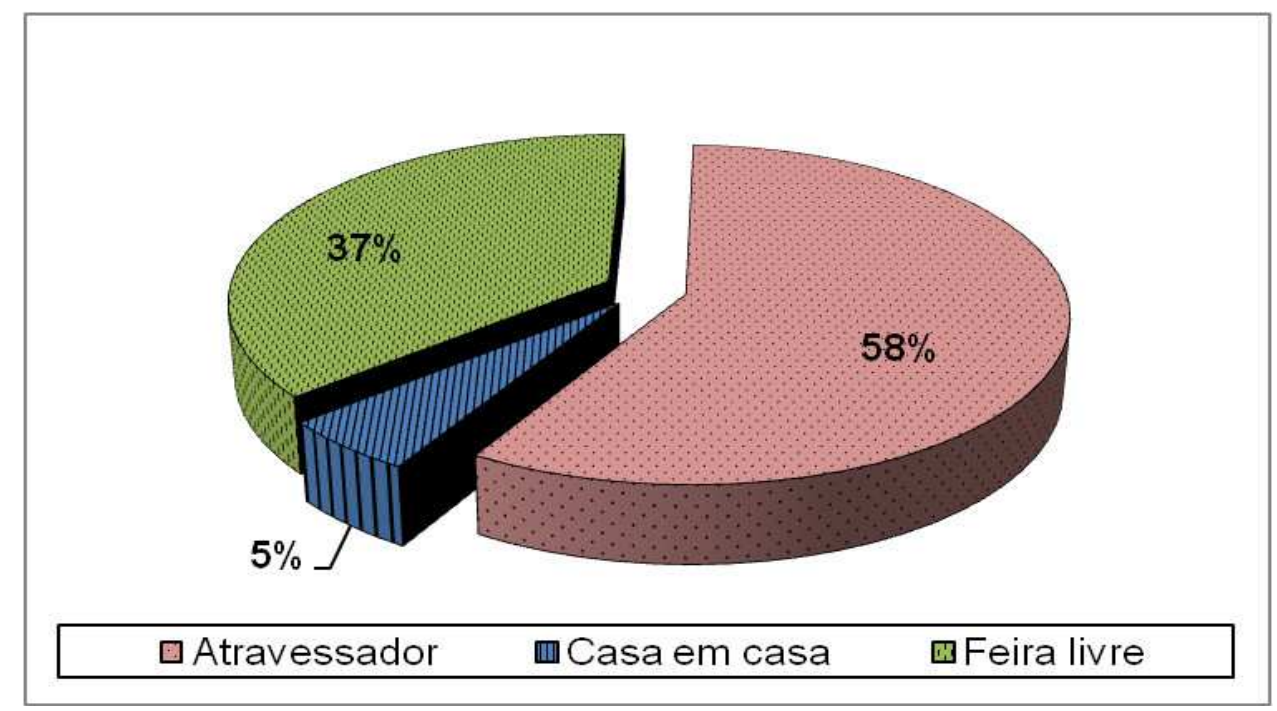

FIGURA 3. Principais destinos de comércio da produção excedente nas unidades de produção familiar de Candiba-BA, 2016.

Quanto à resposta sobre assistência técnica rural, 94\% dos agricultores disseram não possuir. O mais preocupante é que este mesmo percentual dos agricultores utiliza agrotóxico, sendo, deste total, 68\% usam constantemente e $25 \%$ usam somente no tratamento de sementes. Dentre os produtos mais utilizados $50 \%$ são altamente perigosos ao meio ambiente e extremamente tóxico a exposição humana, como os inseticidas de nome comercial: Brilhante, Cyptrim $250 \mathrm{CE}$ e Klorpan 480 EC. Além disso, utilizam produtos que não são registrados para cultura alvo, ou mesmo produtos para fins veterinários (Barrage) no tratamento de sementes; não fazem uso do equipamento de proteção individual (EPI); não devolvem as embalagens vazias dos agrotóxicos; ignoram as orientações (bula dos produtos), ocorrendo uso demasiado.

Diante da falta de assistência técnica e extensão rural, os agricultores buscam informações agropecuárias em outros meios como: programas de rádio, programas de televisão, revistas agropecuárias, reunião e encontros da associação, internet e por meio do compartilhamento de informações entre amigos e vizinhos (Figura 4). Sendo os programas de rádio e televisão os principais agentes informantes, representando 34 e $25 \%$ respectivamente.

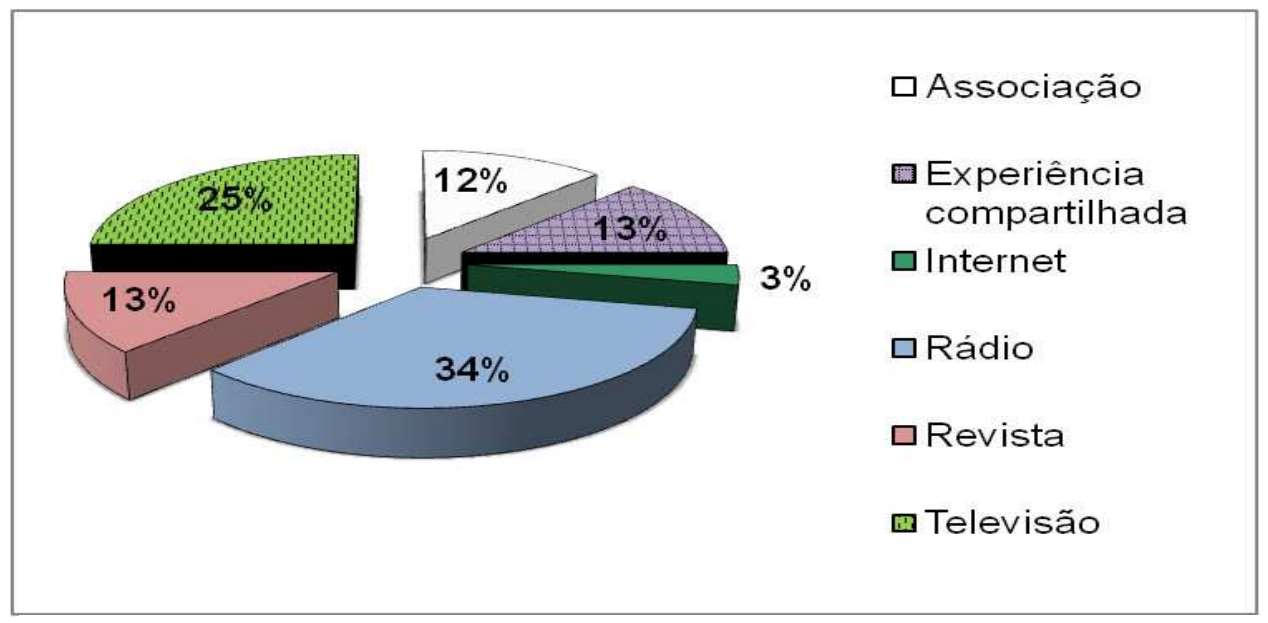

FIGURA 4. Fontes de informação agropecuária para os agricultores familiares de Candiba-BA, 2016. 
Em relação aos créditos agrícolas, todos os agricultores já foram ou estão sendo contemplados por algum. Dentre os créditos agrícolas, o Programa Nacional de Fortalecimento da Agricultura Familiar (PRONAF) é responsável pelo financiamento de $79 \%$ dos agricultores, ainda, $16 \%$ participam do Agroamigo, que é um programa de microfinança rural do Banco do Nordeste, destinado a agricultores familiares enquadrados em alguns grupos do PRONAF. Já para o financiamento privado, a participação dos agricultores é de apenas 5\% (Figura 5).

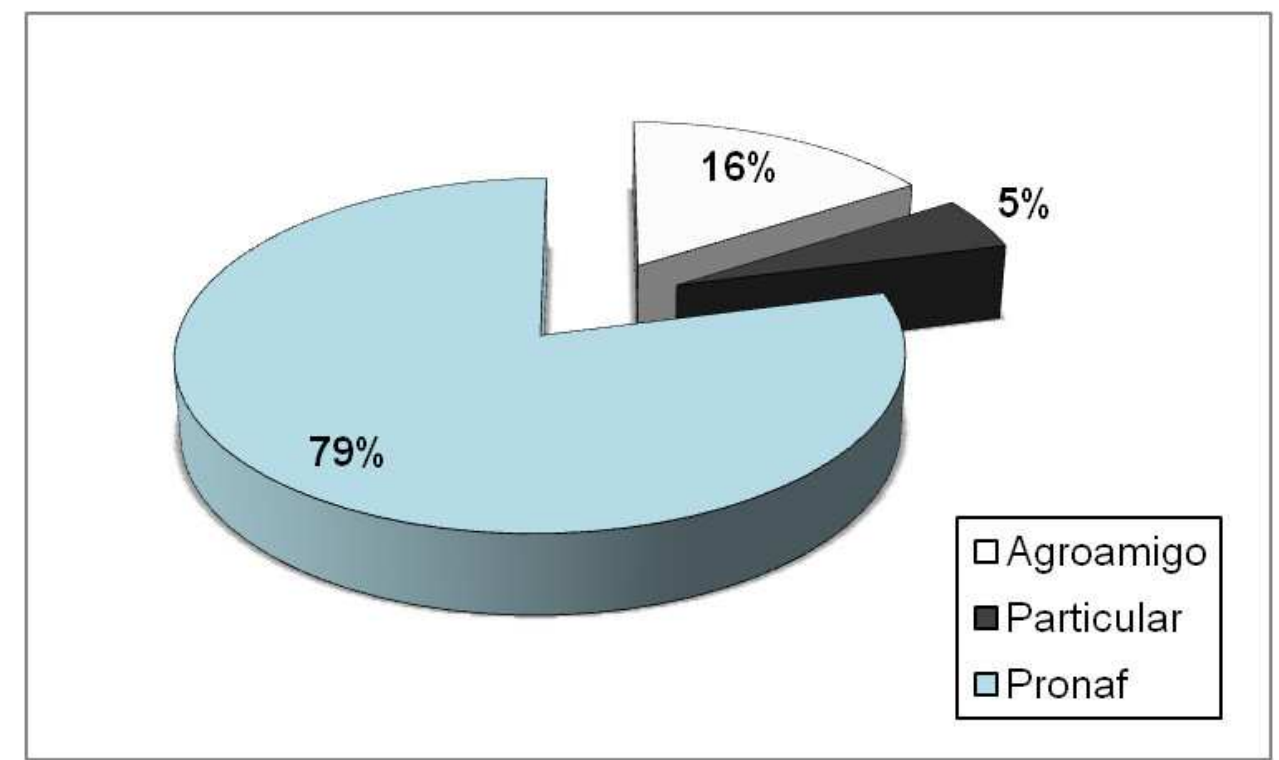

FIGURA 5. Participação dos agricultores familiares aos créditos agrícola em Candiba-BA, 2016.

Segundo WESZ JÚNIOR (2010), o PRONAF foi criado para subsidiar os produtores rurais que se encontravam sem capital para investir em suas propriedades, visto que as políticas agrícolas implantadas anteriormente no país beneficiaram apenas ao grande latifúndio e o agricultor familiar encontrava-se em situação decadente. Nesse sentido, o PRONAF é uma política de crédito, que vem transformando a pequena produção rural, fazendo com que o homem do campo se firme no seu local de origem e ainda aumentando a quantidade dos alimentos produzidos por este segmento econômico.

Quanto aos benefícios de políticas públicas voltadas para a convivência com o semiárido, $88 \%$ dos agricultores familiares receberam as cisternas do programa Água para Todos do Governo Federal, com capacidade para armazenar 16000 litros de água. Tratando-se de uma região em que se predomina o clima semiárido com ocorrência de pequenos períodos de chuvas sazonais, a criação de alternativas para conviver com esse fator limitante torna-se de fundamental importância. Para Neto (2015), a utilização destas cisternas é uma das técnicas mais viáveis para convivência com o semiárido e uma forma de mitigar os efeitos da escassez de água para consumo humano.

\section{CONCLUSÕES}

Os agricultores familiares em sua maioria utilizam agrotóxicos de forma indiscriminada e não conhecem os danos que provocam ao ambiente e a saúde humana. 
É necessária assistência técnica que valorize os saberes tradicionais e maximize a utilização dos recursos naturais de forma sustentável.

A agricultura familiar tem importante destaque, tanto na economia interna do município como a nível territorial e garante o acesso da população aos alimentos.

A comercialização dos produtos da agricultura familiar carece de organização para reduzir a interferência do atravessador

\section{REFERÊNCIAIS}

FERREIRA, P. A.; PEREIRA, J. R.; ALENCAR, E.; SANTANA, A. C. Estado e agricultores familiares: uma análise interpretativa sobre o desenvolvimento rural no Sul de Minas Gerais. Revista de Economia e Sociologia Rural, v. 47, n. 3, p. 769792, 2009. Disponível em: <http://www.scielo.br/scielo.php?pid=S010320032009000300011\&script=sci_arttext\&tlng=pt>. Acesso em: 01 out. 2016. doi: 10.1590/S0103-20032009000300011

IBGE. Instituto Brasileiro de Geografia e Estatística. Censo 2006. Disponível em: http://www.bb.com.br/docs/pub/siteEsp/agro/dwn/CensoAgropecuario.pdf. Acesso em: 31 ago. 2016.

IBGE. Instituto Brasileiro de Geografia e Estatística. Censo 2010. Disponível em: $<$ http://www.censo2010.ibge.gov.br/sinopse/index.php?uf=29\&dados=0 $>$. Acesso em: 01 out. 2016.

INCRA. Instituto Nacional de Colonização e Reforma Agrária. Sistema nacional de cadastro rural. Disponível em: http://www.incra.gov.br/tabela-modulo-fiscal. Acesso em: 02 set. 2016.

Ministério do Desenvolvimento Agrário. Plano Territorial de Desenvolvimento Rural sustentável do Sertão Produtivo. 1ª ed. 2010. 124p.

NASCIMENTO, F. S.; BESKOW, P. R. Comercialização e organização dos produtores agroecológicos no Rio Grande do Sul - o estudo das experiências da associação agricultores ecologistas de Ipê e Antonio Prado - AECIA e Centro de Apoio ao Pequeno Agricultor. Redes, v. 20, n. 2, p. 261-282, 2015. Disponível em: <https://online.unisc.br/seer/index.php/redes/article/view/2432>. Acesso em: 30 set. 2016. doi:10.17058/redes.v20i2.2432

NETO, M. M. Convivência com o semiárido: nas fronteiras entre o novo que se legitima e o antigo que teima em ficar. Novos Cadernos NAEA, v. 18, n. 1, p.169182, 2015.2 Disponível em: <http://periodicos.ufpa.br/index.php/ncn/article/viewArticle/2038> Acesso em: 02 out. 2016. doi: 10.5801/ncn. v18i1. 2038

SANTOS, A. S.; XAVIER, J. F.; FERREIRA, B. M.; SILVA, R. C.; ALVES, S. A. F. Diagnóstico da produção da agricultura familiar dos Agricultores do Município de Lagoa Seca, PB. Cadernos de Agroecologia, v. 8, n. 2, p.1-5, 2013. Disponível em: <http://aba-agroecologia.org.br/revistas/index.php/cad/article/view/14663/9340> 
WESZ JUNIOR, V. J. Política pública de agroindustrialização na agricultura familiar: uma análise do Pronaf-Agroindústria. Revista de Economia e Sociologia Rural, v. 48, n. 4, p. 567-596, 2010. Disponível em: < http://www.scielo.br/scielo.php?pid=S0103-

20032010000400004\&script=sci_arttext\&tlng=es>. Acesso em: 01 de out. 2016. doi:10.1590/S0103-20032010000400004 